\title{
A PRESENÇA DE FEUERBACH NOS MANUSCRITOS DE 1844 DE MARX
}

\author{
Mônica Hallak ${ }^{1}$
}

\begin{abstract}
Resumo
O presente artigo tem como referência central a dissertação de Mestrado defendida por Rodrigo Alckmin no Programa de Pós Graduação em Filosofia da UFMG em 2003: Feuerbach e Marx - da sensibilidade à atividade sensível. O trabalho de Alckmin insere-se em um projeto mais amplo, coordenado pelo Professor José Chasin, que buscou reconstruir, através da leitura e análise de rascunhos, cartas, artigos e livros do período entre 1841 e 1847, os passos iniciais de Marx na constituição de sua própria abordagem. Os estudos realizados no interior desse projeto referenciam-se na publicação, em 1995, do texto Marx: estatuto ontológico e resolução metodológica, no qual Chasin sistematizou os resultados da pesquisa empreendida por ele que apontavam a necessidade de estudos mais aprofundados de determinados autores e temas que marcaram a obra de Marx no período de formação. É, portanto, com o intuito de compreender a influência de Feuerbach no processo inicial da formulação de Marx, que Alckmin elege o autor de Princípios da Filosofia do futuro como tema de pesquisa. Como o objetivo aqui é apresentar especificamente a presença de Feuerbach nos Manuscritos de 1844, será resgatada também parte da análise, desenvolvida no interior do mesmo projeto, presente na dissertação As categorias Lebensäusserung, Entäusserung, Entfremdung e Veräusserung nos Manuscritos Econômico-filosóficos de Karl Marx de 1844, na qual a reivindicação da sensibilidade, herdada de Feuerbach, aparece de forma direta. Os resultados das pesquisas apresentadas nos três trabalhos - Chasin (1995), Alckmin (2003) e Hallak (1999) - tanto confirmam a presença decisiva de Feuerbach na constituição do itinerário marxiano, quanto apontam as diferenças entre os dois autores que podem ser identificadas já nos rascunhos de 1844 .
\end{abstract}

Palavras-Chave: Feuerbach, Marx, sensibilidade.

\begin{abstract}
:
This paper has as its central reference to Rodrigo Alckmin's Master degree thesis defended at UFMG's Graduate Program in Philosophy, in 2003: Feuerbach and Marx - from sensitivity to sensitive activity. Alckmin's work fits into a broader project, coordinated by Professor José Chasin, who sought to reconstruct Marx's initial steps, through reading and analyzing drafts, letters, articles and books from the period between 1841 and 1847. The studies carried out within this project make reference to the 1995 publication "Marx: ontological status and methodological resolution", in which Chasin systematized his research results, which pointed to the need for further study of certain authors and themes that marked the Marx's intial work. It is therefore in order to understand the influence of Feuerbach in the initial process of Marx's formulation that Alckmin elects the author of "Principles of the Future of Philosophy" as a subject of research. Since the goal of this paper is to specifically demonstrate Feuerbach's presence in the 1844 Manuscripts, part of the analysis, developed within the same project, will be covered as it pertains to the dissertation on "The Lebensäusserung Entdusserung, Entfremdung and Veräusserung Categories in Karl Marx’s 1844 Economic and Philosophical Manuscripts”, in which Feuerbach's sensitivity is directly shown. Research results presented in three papers - Chasin (1995), Alckmin (2003), and Hallak (1999) -confirm the decisive presence of Feuerbach in the constitution of the Marxian itinerary, and point out the differences between the two authors, differences that can already be identified in the 1844 manuscript.
\end{abstract}

Keywords: Feuerbach, Marx, sensitivity.

Com o propósito de rastrear a influência que Feuerbach exerceu sobre Marx, Rodrigo Alckmin (2003) buscou inicialmente apresentar as reflexões de Feuerbach no contexto em que foram elaboradas. É quando esclarece algumas questões que contribuem

\footnotetext{
${ }^{1}$ Graduada em Serviço Social pela PUC Minas (1985), mestre em Filosofia pela UFMG (1999) e doutora em Serviço Social pela UFRJ (2010). Atualmente é assistente social da Secretaria de Saúde do Estado de Minas Gerais e professora da Escola de Serviço Social da PUC Minas. Tem experiência nas áreas de Filosofia e Serviço Social, atuando principalmente nos seguintes temas: alienação, teoria social em Marx, história do Serviço Social.
} 
Mônica Hallak. para compreender o itinerário feuerbachiano. Ele afirma que a obra de Feuerbach foi, em grande parte, desmerecida por estar "encravada entre dois gigantes da história da filosofia, a saber, Hegel e Marx", o que acabou por obscurecer os escritos de Feuerbach.

A pesquisa de Alckmin revela que já na tese doutoral, em que Feuerbach pretendia realizar uma assimilação "viva" e "livre" das aulas de Hegel, o princípio da materialidade sensível aparece quando afirma a necessidade de a ideia descer do "firmamento de sua pureza incolor e da unidade consigo mesma em direção a uma visão imediata que penetra o particular, a fim de se incorporar o dado dos fenômenos aparentes" (Löwith apud Alckmin, 2003, p.18). Löwith também observa como a reivindicação da sensibilidade aparece na tese:

O puro logos tem necessidade de uma 'Encarnação', a Idéia reivindica uma 'realização' e uma 'mise au monde'. /.../ Ele justifica seu desejo de reconduzir a Idéia sobre a terra, declarando que esse desejo está 'conciliado com a época' ou, 'o que é a mesma coisa', fundado sobre o espírito mesmo da filosofia hegeliana, pois não se trata de uma tarefa de escola, mas uma tarefa da humanidade (Löwith apud Alckmin, 2003, p.18).

Provavelmente, a reivindicação da terrenalidade já seria suficiente para impactar Marx em 1844. Mas os trabalhos posteriores ampliam ainda mais a identificação entre os dois autores.

Em 1830, Feuerbach publica anonimamente Pensamentos sobre morte $e$ a imortalidade, livro responsável pela sua exclusão da carreira como professor universitário. Segundo McLellan, citado por Alckmin: "Feuerbach argumenta aqui contra toda classe de imortalidade individual, sendo possível somente a imortalidade do espírito humano como conjunto, e substitui a transcendência divina pela transcendência humana" (McLellan apud Alckmin, 2003, p. 18). Afastado da carreira docente, Feuerbach casa-se e muda-se para o campo, o que o levou a viver próximo à natureza, peculiaridade que, no entender de Alckmin, "encontra reflexo em sua produção intelectual” (Alckmin, 2003, p. 18). De fato, em Preleções sobre a essência da religião, Feuerbach afirma: “[...] eu não passei a mais bela parte da minha vida numa cátedra e sim no campo, não em aulas universitárias mas no templo da natureza, não em salões e salas de audiências mas na solidão de meu quarto de estudos" (Feuerbach apud Alckmin, 2003, p. 18).

\begin{tabular}{|l|l|l|l|l|}
\hline Q Povista Qialectus & Ano 2 & n. 6 & Janeiro - Agosto 2015 & p. 108-119 \\
\hline
\end{tabular}


Em Contribuição à crítica do direito de Hegel de 1839, a natureza aparece como princípio filosófico, diz ele:

\begin{abstract}
É falso conceber a natureza em contradição com a liberdade moral. A natureza não constitui somente a maquinaria elementar do estômago, ela também erigiu o templo do cérebro; [...] A natureza somente se ergue contra a liberdade do imaginário, mas ela não contradiz a liberdade racional.Todo copo de vinho que nós bebemos em demasia é uma prova patética e mesmo peripatética que a servidão à paixão revolta o sangue (Feuerbach apud Alckmin, 2003, p.32).
\end{abstract}

A reivindicação da sensibilidade é afirmada em Essência do Cristianismo, quando se lê:

Sou astronomicamente diferente dos filósofos que arrancam os olhos da cabeça para poderem pensar melhor; eu, para pensar, necessito dos sentidos, mas, acima de todos, dos olhos; fundamento minhas idéias sobre materiais que podemos buscar sempre através da atividade dos sentidos; não produzo coisas a partir do pensamento, mas inversamente os pensamentos a partir das coisas, mas coisa é somente o que existe fora da cabeça (Feuerbach apud Alckmin, 2003, p. 39).

Após apresentar, em diversos escritos feuerbachianos, a reivindicação da sensibilidade em detrimento à abstração do idealismo, Alckmin constata que mesmo que a crítica de Feuerbach à especulação centre-se na demanda pela realidade dos sentidos, ele diferencia o homem do animal pela consciência. E mais: após afirmar a natureza e a sensibilidade como princípios filosóficos, "surpreendentemente", diz Alckmin, Feuerbach “identifica ser e consciência"2 (Alckmin, 2003, p.72); enquanto Marx, já em 1844, reivindica a atividade sensível como traço distintivo do homem. Esta importante diferença entre Feuerbach e Marx dos Manuscritos de 1844 será valorizada na análise que se segue.

É especialmente na crítica à especulação, desenvolvida no terceiro manuscrito, que a influência feuerbachiana aparece de forma direta nos rascunhos de Marx de 1844. Nesse momento do texto, dedicado à análise da Fenomenologia deHegel, Marx trata do caráter objetivo de toda ação humana denunciando a absurdidade do ser abstrato da especulação. Suas palavras são claras:

\footnotetext{
2"O ser, com que a filosofia começa, não pode separar-se da consciência, nem a consciência pode separar-se do ser. Assim, como a realidade da sensação é a qualidade e,inversamente, a sensação é a realidade da qualidade, assim também o ser é a realidade da consciência, mas, inversamente, a consciência é a realidade do ser - só a consciência é o ser efetivamente real. A unidade real de espírito e natureza é unicamente a consciência" (Feuerbach apud Alckmin, 2003, p. 72).
}

\begin{tabular}{|l|l|l|l|l|}
\hline Renista 2 Halleatus & Ano 2 & n. 6 & Janeiro - Agosto 2015 & p. 108-119 \\
\hline
\end{tabular}


Mônica Hallak.

Um ser que não tenha sua natureza fora de si não é um ser natural, não faz parte da essência da natureza. Um ser que não tem nenhum objeto fora de si não é um ser objetivo. Um ser que não é por sua vez objeto para um terceiro ser não tem nenhum ser como objeto seu, isto é, não se comporta objetivamente, seu ser não é objetivo. Um ser não objetivo é um não-ser (Marx, 2004, p.127) .

Trata-se, como mostra Alckmin, "de um reposicionamento intrínseco dos Princípios da Filosofia do Futuro", onde se lê: "O ser no pensamento, o ser sem objetividade, sem efetividade, sem ser-para-si é, certamente, nada; mas neste nada, expresso apenas a niilidade da minha abstração" (Feuerbach apud Alckmin, 2003, p. 108).

É inspirado em Feuerbach que Marx se reporta à objetividade enquanto fundamento de todo ser, situando o seu caráter relacional como a primeira evidência desta determinação. Marx procura demonstrar como esta determinação se apresenta na existência concreta:

A fome é um carecimento natural; precisa, pois, de uma natureza fora de si, um objeto fora de si para satisfazer-se, para acalmar-se. A fome é a necessidade confessa que meu corpo tem de um objeto que está fora dele e é indispensável para sua integração e para sua exteriorização essencial (Marx, 2004, p.127)

Como mostra Alckmin (2003, p. 109), a "analogia com as Teses Provisórias para a Reforma da Filosofia é gritante no momento em que Feuerbach associa ao ser o caráterinalienável de padecimento". Nas palavras de Feuerbach:

Só o ser indigente é o ser necessário. A existência sem necessidades é uma existência supérflua. O que é em geral isento de necessidades também não tem qualquer necessidade da existência. Quer ele seja ou não é tudo um - um para si mesmo, um para os outros. Um ser sem indigência é um ser sem fundamento. Só merece existir o que pode sofrer (Feuerbach apud Alckmin, 2003, p. 109).

\footnotetext{
${ }^{3}$ As referências que aparecem no texto são da edição brasileira Manuscritos Econômico-filosóficos São Paulo: Boitempo editorial, 2004 tradução: Jesus Raniere. Em nota de rodapé são apresentadas as referências das edições francesa - Manuscrits de 1844 (Économie politique e philosophie) Paris: Ed. Sociales, 1972 tradução: Émile Bottigelli - e alemã - Ökonomisch-philosophische Manuskripte aus dem jahre 1844 Dietz Verlag Berlin, 1985. Marx, 1972, p. 137 e 1985, p. 578

${ }^{4}$ Marx, 1972, p. 137 e 1985 , p. 578
}

\begin{tabular}{|l|l|l|l|l|}
\hline Q Povista Dialectus & Ano 2 & n. 6 & Janeiro - Agosto 2015 & p. 108-119 \\
\hline
\end{tabular}


Mônica Hallak.

Nesta linha, Marx afirma, nos Manuscritos de 1844, "ser sensível, isto é, ser efetivo, é ser objeto dos sentidos, é ser objeto sensível, e, portanto, ter objetos sensíveis fora de si, ter objetos de sua sensibilidade. Ser sensível é ser padecente" (Marx, 2004, p. 128) ${ }^{5}$.

Mas, mesmo nos momentos em que as afirmações de Marx aparecem como puro eco dos escritos de Feuerbach as diferenças já podem ser identificadas. É o que ocorre quando Marx afirma:

como ser natural, corpóreo, sensível, objetivo, [o homem] é um ser que sofre, dependente e limitado, tal qual o animal e a planta; isto é, os objetos de suas pulsões existem exteriormente como objetos independentes dele. Mas (grifo meu), esses objetos são objetos de seu carecimento, objetos essenciais, indispensáveis para a atuação e confirmação de suas forças essenciais (Marx, 2004, p.127).

Em comum com a natureza, o homem é um ser corpóreo, sensível, objetivo, ou seja, "dependente e limitado". Como qualquer outro ente natural, ele necessita de objetos exteriores, "como objetos independentes dele". Mas, em seguida, Marx salienta que "esses objetos são objetos de seu carecimento", ou seja, "objetos essenciais", sem os quais ele não se efetiva como homem.

Como afirma Hallak, a

subsunção natural aparece como determinante apenas pelos seus limites, pelo condicionamento objetivo que, no entanto, não aprisiona o ser humano. Ao contrário, "como ser natural ativo", ele transforma o carecimento em "confirmação de suas forças essenciais". Assim, Marx situa o ser ativo como entificação peculiar que transcende os limites naturais, pois é capaz de se pôrcomo uma objetividade sensível que apresenta atributos específicos (Hallak, 2001, p. 169).

Pois, para Marx, "no tipo de atividade vital reside todo caráter de uma espécie, seu caráter genérico, e a atividade livre consciente, é o caráter genérico do homem" (Marx, 2004, p. 84) ${ }^{7}$; isto significa que o "homem faz de sua atividade vital objeto de sua vontade e de sua consciência. Possui atividade vital consciente" (Marx, 2004, p. 84) ${ }^{8}$. Em sua atividade, o homem não se reproduz enquanto mero ser natural, mas enquanto ser genérico, pois sua atividade possui outra legalidade, outro estatuto que não o simplesmente natural.

\footnotetext{
${ }^{5}$ Marx, 1972, p. 138 e 1985 , p. 579.

${ }^{6}$ Marx, 1972, p. 136 e 1985, p. 578.

${ }^{7}$ Marx, 1972, p. 62 e 1985, p. 516.

${ }^{8}$ Marx, 1972, p. 63 e 1985, p. 516.
}

\begin{tabular}{|l|l|l|l|l|}
\hline Q Poxista 2 Dialectus & Ano 2 & n. 6 & Janeiro - Agosto 2015 & p. 108-119 \\
\hline
\end{tabular}


Mônica Hallak.

Desse modo, mesmo atribuindo a Feuerbach o mérito de ter fundado o "verdadeiro materialismo e a ciência real" (Marx, 2004, p. 118) é o próprio Marx quem identifica na atividade a característica distintiva entre homem e os demais entes naturais.

Se nos momentos em que assume diretamente a influência feuerbachiana, Marx, dos Manuscritos de 1844, atribui a Feuerbach méritos pela compreensão da especificidade dA objetividade humana, nas passagens em que dialoga com outros autores percebe ainda menos o ineditismo de sua própria formulação.

No complemento ao segundo manuscrito, intitulado Propriedade Privada $e$ comunismo, a "identidade entre ser e objetividade aparece [...] como forma peculiar da existência dos homens, numa reconfiguração que transforma a necessidade de objetos exteriores na confirmação das forças essenciais humanas" (Hallak, 2001, p. 169). Para Marx essa reconfiguração só é possível em sociedade:

A essência humana da natureza está, em primeiro lugar, para o homem social; pois é primeiro aqui que ela existe para ele na condição de elo com o homem, na condição de existência sua para o outro e do outro para ele; é primeiro aqui que ela existe como fundamento de sua própria existência humana, assim como também na condição de elemento vital da efetividade humana. É primeiro aqui que sua existência natural se lhe tornou para ele sua existência humana e a natureza [se tornou] para ele o homem. Portanto, a sociedade é a unidade essencial completada do homem com a natureza, a verdadeira ressurreição da natureza, o naturalismo realizado do homem e o humanismo da natureza levado a efeito (Marx, 2004, p. 106-7) ${ }^{10}$.

Portanto, afirma Hallak (2001, p. 169), "somente para o ser social o vínculo com a natureza é ao mesmo tempo sua relação com os demais homens e apenas desse modo a inter-relação entre os homens se realiza na relação com a objetividade natural que, assim, reemerge como objetividade social”. Ou seja, já em 1844, Marx capta o gênero humano como vínculo social e não como "generalidade interna, muda, que une muitos indivíduos de modo meramente natural" (Marx, 2007, p. 538) como dirá no ano seguinte nas teses Ad Feuerbach.

Em carta dirigida a Feuerbach em agosto de 1844, Marx entende que Feuerbach ofereceu uma fundamentação filosófica para o socialismo ao conceber a unidade do homem com o homem baseada nas diferenças reais entre eles e ao situar o conceito de

\footnotetext{
${ }^{9}$ Marx, 1972, p. 127 e 1985, p. 570.

${ }^{10}$ Marx, 1972, p. 89 e 1985 , p. 537-8.
}

\begin{tabular}{|l|l|l|l|l|}
\hline Q Ponista Dialectus & Ano 2 & n. 6 & Janeiro - Agosto 2015 & p. 108-119 \\
\hline
\end{tabular}


gênero humano na terra real e não no céu da abstração. Mas, mesmo nesse momento, as diferenças já podem ser notadas, pois a reivindicação da atividade sensível - e não da sensibilidade natural - e da sociabilidade - e não a relação eu-tu - aparecem nos rascunhos de 1844 como traços distintivos entre o materialismo de Feuerbach e o de Marx.

Os dois aspectos mencionados acima se articulam nas considerações de Marx acerca da constituição dos sentidos:

Cada uma das suas [do homem] relações humanas com o mundo, ver, ouvir, cheirar, degustar, sentir, pensar, intuir, perceber, querer, ser ativo, amar, enfim todos os órgãos da sua individualidade, assim como os órgãos que imediatamente em sua forma como órgãos comunitários, são no seu comportamento objetivo ou no seu comportamento para com o objeto a apropriação do mesmo, a apropriação da efetividade humana; seu comportamento para com o objeto é o acionamento da efetividade humana (por isso ela é precisamente tão multíplice quantos multíplices são as determinações essenciais e atividade humanas), eficiência humana e sofrimento humano, pois o sofrimento, humanamente apreendido, é uma autofruição do ser humano (Marx, 2004, p. 91). ${ }^{11}$

A citação acima e seus desdobramentos são exemplares no sentido de tornar possível a identificação tanto da influência exercida pelos escritos de Feuerbach nos rascunhos de Marx de 1844, quanto dos elementos da formulação marxiana que superam Feuerbach naquele momento.

Marx situa a apropriação como ato genérico, que produz a objetividade social na forma da exterioridade sensível e da sensibilidade humana. Ele o faz em estilo direto: "O olho se tornou olho humano, da mesma forma que seu objeto se tornou um objeto social humano, proveniente do homem para o homem" (Marx, 2004, p. 109) ${ }^{12}$, pois o objeto apropriado pelo homem se converte em objetividade social. Do mesmo modo os órgãos dos sentidos humanos, nessa apropriação, transformam-se continuamente em sentido universal. "Imediatamente em sua práxis os sentidos se tornaram teoréticos. Relacionam-se com a coisa por querer a coisa, mas a coisa mesma é um comportamento humano objetivo para consigo própria e para com o homem e vice-versa" (Marx, 2004, p. 109) ${ }^{13}$, pois, em sua prática, os sentidos sabem concretamente de si e da coisa ${ }^{14}$.

\footnotetext{
${ }^{11}$ Marx, 1972, p. 91 e 1985, p. 539

${ }^{12}$ Marx, 1972, p. 92 e 1985, p. 540.

${ }^{13}$ Marx, 1972, p. 92 e 1985, p. 540.

${ }^{14}$ Alckmin lembra que Feuerbach em "Princípios da Filosofia do Futuro se refere à ligação entre a arte e os sentidos, sem perder de vista os resquícios de um raciocínio composto por rudimentos religiosos. Contrariando a filosofia especulativa, que concebe o absoluto como o objeto da arte,
}

\begin{tabular}{|c|c|c|c|c|}
\hline Pevita $\bar{a}$ & Ano 2 & n. 6 & Janeiro - Agosto 2015 & p. $108-119$ \\
\hline
\end{tabular}


Mônica Hallak.

Desse modo, "a carência ou a fruição perderam [...] sua natureza egoísta e a natureza a sua mera utilidade, na medida em que a utilidade se tornou utilidade humana" (Marx, 2004, p. 109) ${ }^{15}$. Ou, como afirma Hallak (2001, p. 174-5), “o objeto exterior como relação humana objetiva se converte em vida e não apenas em algo que sacia uma necessidade imediata, pois o carecimento humano se satisfaz na apropriação humana e, portanto, multilateral, não somente para o ser individual, mas para o gênero". Nas palavras de Marx: "o sentido e o espírito do outro homem se tornaram minha própria apropriação" (Marx, 2004, p. 109) (92/540), propiciando para a atividade e para os sentidos um vasto campo de atuação concreta tanto individualmente como em conjunto, pois "além destes órgãos imediatos se constituem, por isso, órgãos sociais, na forma da sociedade, assim, por exemplo, a atividade imediatamente na sociedade com os outros etc. tornou-se um órgão de minha externação de vida e um modo de apropriação da vida humana" (Marx, 2004, p. $109)^{16}$.Hallak compreende, assim, que

o sentido e o gozo dos outros homens, a vida social, aparece ela mesma como apropriação de cada homem, pois posso me apropriar do modo de apropriação do outro: posso ouvir com os outros, ver com os olhos dos outros, constituir assim meus próprios órgãos dos sentidos a partir da sensibilidade do outro (Hallak, 2001, p. 175).

Por outro lado, Hallak complementa, "a própria vida social, a atividade social torna-se órgão por excelência da exteriorização da vida humana, pois, para além dos órgãos dos sentidos imediatamente físicos (que são sociais em sua forma), o sentido e o gozo do conjunto dos homens é a forma do humano se expressar" (Hallak, 2001, p. 175).

Assim, a apropriação humana é universal porque a apropriação de todos os homens se converte em apropriação de cada homem e vice-versa, o objeto de cada apropriação particular é ao mesmo tempo, apropriação universal. Nesse sentido, Marx afirma:

[...] quando, por um lado, para o homem em sociedade, a efetividade objetiva se torna em toda parte em efetividade das forças essenciais humanas, enquanto efetividade humana, e por isso, efetividade de suas próprias forças essenciais, todos os objetos tornam-se [a] objetivação de si mesmo para ele, objetos que realizam e confirmam sua individualidade,

Feuerbach remete as produções artísticas, diretamente, ao gozo dos sentidos. Por conseguinte, essência divina e sentidos possuem uma conexão, naturalmente, tomando o homem como 0 verdadeiro objeto dessa relação." (Alckmin, 2003, p. 92).

${ }^{15}$ Marx, 1972, p. 92 e 1985, p. 540.

${ }^{16}$ Marx, 1972, p. 92 e 1985, p. 540.

\begin{tabular}{|l|l|l|l|l|}
\hline Govista Dialectus & Ano 2 & n. 6 & Janeiro - Agosto 2015 & p. 108-119 \\
\hline
\end{tabular}


Mônica Hallak. enquanto objetos seus, isto é, ele mesmo torna-se objeto (Marx, 2004, p. $110)^{17}$.

Porquanto, toda objetividade social da qual e na qual o homem vive é sua própria produção, toda ela é a expressão sensível de que o mundo que ele cria é o seu mundo, no qual cada objeto é a confirmação de si mesmo, mas "como se tornam seus, depende da natureza do objeto e da natureza da força essencial que corresponde a ela, pois precisamente a determinidade dessa relação constitui o modo particular, real da afirmação" $\left(\right.$ Marx, 2004, p. 110) ${ }^{18}$. Ou seja, na realidade concreta, a apropriação é uma relação que envolve o objeto em sua especificidade e a força essencial humana em sua capacidade particular de apropriação. Nessa relação, o objeto se afirma enquanto objeto humano na mesma medida em que a força essencial que lhe corresponde for a expressão da universalidade do homem.

Os sentidos se humanizam, confirmam-se enquanto força essencial a partir do grau de apropriação da sua capacidade universal. Usando o próprio exemplo de Marx, o ouvido de cada homem torna-se musical a partir da apropriação do ouvir humano possível naquele momento. Sem essa apropriação o seu sentido não é capacidade subjetiva, isto é, não tem condições para a apropriação humana, não tem na "mais bela música" um objeto, pois suas forças essenciais não são capazes de fruí-la.

Por outro lado, mas na mesma linha de reflexão, "é somente graças à riqueza objetivamente desenvolvida da essência humana que a riqueza da sensibilidade humana subjetiva é em parte desenvolvida, em parte criada, que o ouvido se torna musical, que o olho percebe a beleza da forma, em resumo, que os sentidos se tornam capazes do gozo humano, tornam-se sentidos que se confirmam como forças essenciais humanas" (Marx, 2004, p. 110) ${ }^{19}$. Para Marx, portanto, a objetividade é o solo, o momento preponderante para o surgimento e desenvolvimento da sensibilidade humana. Essa, por sua vez, torna-se capaz de engendrar objetividades direcionadas para a realização humana. Tal engendramento, por seu turno, torna-se a base de um novo patamar da sensibilidade e assim sucessivamente, numa contínua interação entre objetividade que se transforma em sensibilidade que, por sua vez, se transforma em nova objetividade.

\footnotetext{
${ }^{17}$ Marx, 1972, p. 92 -3 e 1985, p. 541.

${ }^{18}$ Marx, 1972, p. 93 e 1985, p. 541.

${ }^{19}$ Marx, 1972, p. 93 e 1985, p. 541.
}

\begin{tabular}{|l|l|l|l|l|}
\hline Q & Dovista \\
\hline
\end{tabular}


Mônica Hallak.

Esse intercâmbio é, antes de mais nada, intercâmbio entre os homens, pois "não só os cinco sentidos, como também os chamados sentidos espirituais, os sentidos práticos (vontade, amor etc.), em uma palavra, o sentido humano, a humanidade dos sentidos, vêm a ser unicamente mediante a existência de seu objeto, mediante a natureza humanizada"(Marx, 2004, p. 110) ${ }^{20}$. A objetivação da vida humana, portanto, produz simultaneamente objetividades sociais exteriores ao homem e o próprio homem como ser objetivo a partir da relação dos homens entre si com a natureza humanizada. Esta, enquanto objeto do homem, é a própria sociedade, é, assim, o homem mesmo em sua expressão genérica. A sensibilidade humana se constitui somente no interior dessas condições, pois a "A formação dos cinco sentidos é um trabalho de toda história universal até nossos dias" (Marx, 2004, p. 110) ${ }^{21}$ e continuará sendo enquanto a humanidade existir.

Marx procura demonstrar essa realidade voltando-se para o modo atual da produção humana: "Vê-se como a história da indústria e a existência tornada objetiva da indústria são o livro aberto das forças humanas essenciais, a psicologia humana sensivelmente presente" (Marx, 2004, p. 110) 22 (94/542). Marx afirma, assim, que a ação humana genérica se presentifica na indústria, pois este é o espaço por excelência da produção e reprodução da sensibilidade humana concreta.

O caráter da exteriorização humana tem, portanto, para Marx, já em 1844, sua figura concreta na indústria, que é para ele a síntese das forças humanas materializadas.

Com essa posição, a sensibilidade, para Marx, não aparece como atributo natural, mas como conquista social, ou seja, da relação entre os homens. É neste sentido que Hallak (2001, p. 174) afirma:

[...] pode-se dizer que a apropriação humana é universal porque o sofrimento do homem é universal, na medida em que a vida em sociedade abre um campo de possibilidades de carecimentos, e satisfações de carecimentos, infinitos. No entanto, esse campo de possíveis orienta a apropriação por uma via dada socialmente pelo desenvolvimento histórico e ao mesmo tempo se põe enquanto tal como resultado do conjunto das ações dos indivíduos particulares. Esse caminho de mão dupla é a já mencionada unidade do ser social consigo mesmo em seus polos individual e genérico.

\footnotetext{
${ }^{20}$ Marx, 1972, p. 94 e 1985 , p. 541.

${ }^{21}$ Marx, 1972, p. 94 e 1985, p. 541-2.

${ }^{22}$ Marx, 1972, p. 94 e 1985 , p. 542.
}

\begin{tabular}{|l|l|l|l|l|}
\hline Q Povista Qialectus & Ano 2 & n. 6 & Janeiro - Agosto 2015 & p. 108-119 \\
\hline
\end{tabular}


Compreendendo a novidade da abordagem iniciada por Marx, pode-se concluir com Chasin $(2009$, p.86)

Portanto, a transmigração de Marx ao estatuto de seu pensamento definitivo se deu /.../ em favor de uma ontologia na qual o ser só é reconhecido pela identificação à objetividade, em especial à objetividade social- enfim decifrada como atividade sensível, o que supera em larga escala os indicativos feuerbachianos, em que pese a grande utilidade que tiveram no arranque da trajetória marxiana. Eis o que resume e caracteriza a instauração de seu pensamento original, assim como esclarece a identidade e matrizamento de toda sua elaboração posterior.

Em síntese, o que se pretende evidenciar com esta comunicação é que o alvo, que Feuerbach não atingiu é:

(...) apontar e ressaltar a transitividade entre objetividade e subjetividade, sempre distintas, mas não necessariamente contrárias, nem intransitivas porque contraditórias. Dito de outra maneira, a contraditoriedade entre elas não nega sua transitividade, ao inverso, porque, se intransitivas, nunca poderiam estar em contradição, apenas em círculos inertes e excludentes, como mitos metafísicos /.... Transitividade ou conversibilidade entre objetividade e subjetividade compreende, pois, a dissolução da unilateralidade ou limites desfiguradores, materialistas e idealistas, do sujeito e do objeto: aquele perde a estreiteza de pura interioridade espiritual e este a de mera exterioridade inerte. Pela constatação do intercâmbio, a subjetividade é reconhecida em sua possibilidade de ser coisa no mundo, e a objetividade como dynameis campo de possíveis. O sujeito se confirma pela exteriorização sensível, na qual plasma sua subjetividade, e o objeto pulsa na diversificação, tolerando formas subjetivas ao limite de sua plasticidade, isto é, de sua maleabilidade para ser outro (Chasin, 2009, P. 98).

Conquista marxiana ainda pouco reconhecida e, menos ainda, explorada pelos preconceitos das mais diversas ordens.

\section{Referências Bibliográficas}

ALCKMIN, Rodrigo. Marx e Feuerbach: da Sensibilidade à Atividade Sensível. Belo Horizonte: Faculdade de Filosofia e Ciências Humanas, 2003. Dissertação (Mestrado em Filosofia) - Universidade Federal de Minas Gerais.

CHASIN, José. Marx: estatuto ontológico e resolução metodológica. São Paulo: Boitempo editorial, 2009.

\begin{tabular}{|c|c|c|c|c|}
\hline Qevista Dialectus & Ano 2 & n. 6 & Janeiro - Agosto 2015 & p. $108-119$ \\
\hline
\end{tabular}


FEUERBACH, Ludwig. Princípios da filosofia do futuro.Tradução Artur Mourão. Lisboa: Edições 70, 1988.

HALLAK, Mônica. A exteriorização da vida nos Manuscritos econômico-filosóficos de 1844. In: Ensaios Ad Hominem1, t. IV (Dossiê Marx).São Paulo: Estudos e Edições Ad Hominem, 2001.

MARX, Karl Manuscrits de 1844(Économie, politique e philosophie). Tradução Emile Bottigelli. Paris: Ed. Sociales, 1972.

Manuscritos econômico-filosóficos e outros textos escolhidos. In: Os Pensadores. São Paulo: Abril Cultural,1974.

. Ökonomisch-philosophische Manuskripte aus dem jahre 1844. Berlim: Dietz Verlag, 1985.

Carta a Ludwig Feurbach (Paris, 11 de agosto de 1844). In Marx: Escritos de Juventud. Tradução Wencelao Roces. Mexico: Fondo de Cultura Economica, 1987.

Manuscritos econômico-filosóficos. Tradução Jesus Raniere. São Paulo: Boitempo editorial, 2004.

Teses ad Feuerabach. In MARX, Karl e ENGELS, Friedrich. A ideologia alemã. Tradução Nélio Schneider, Luciano Martorano e Rubens Enderle. São Paulo: Boitempo editorial, 2007.

SCHMIDT, Alfred. Feuerbach o la sensualidad emancipada. Tradução Julio Carabaña. Madrid: Taurus ediciones, 1975. 